\title{
The Contribution of Drama in Education to the Development of Skills Improving the Interpersonal Relations of Multicultural Classroom Students
}

\author{
Nick Mavroudis (Corresponding author) \\ National and Kapodistrian University of Athens \\ 12 Efimou Street, 11632 Athens, Greece \\ Tel: 30-694-782-3865Ｅ-mail: nikolasm1@hotmail.com \\ Pagona Bournelli \\ National and Kapodistrian University of Athens \\ 53 Lykeiou Street, 15341 Agia Paraskevi, Greece \\ Tel: 30-694-521-0476Ｅ-mail: pbournel@phed.uoa.gr
}

Received: July 5, 2019 Accepted: August 23, 2019 Published: August 28, 2019

doi:10.5296/jei.v5i2. $15025 \quad$ URL: https://doi.org/10.5296/jei.v5i2.15025

\begin{abstract}
The aim of this study is to demonstrate the contribution of a drama in education programme, implemented among students of a multicultural elementary school, to advance skills promoting personal empowerment, develop empathy and collaboration, and to improve their interpersonal relationships. The research is a case study, the tools of which are interviews, observation, researcher's log, as well as the assessments and self-assessments of students who participated in the processes. The participants are 21 children with various cultural origins, from the lowest financial strata of Greece. The results of this study highlight drama in education as a valuable pedagogical tool that develops a series of qualitative skills necessary in many aspects of everyday life.
\end{abstract}

Keywords: Drama in education, Empathy, Collaboration, Self-perception, Self-esteem, Interpersonal relationships

\section{Introduction}

According to research data, drama in education may play a positive role in the development 
of socio-emotional skills, which are necessary for a successful social adjustment (Belliveau, 2005; Joronen, Konu, Rankin, \& Åstedt-Kurki, 2011; Lindberg, 2015; Mages, 2010; Mavroudis \& Bournelli, 2016, Mc Naugton, 2010). Such skills, linked to the satisfactory expression of emotions, self-empowerment, the advancement of collaboration and respect for the ideas, interests and needs of other people, improve the interpersonal relationships of children and should be developed by all students at school (Kuranchie \& Addo, 2015). Drama in education is a valuable tool in the promotion of this educational concept.

The participation of students in group drama activities in education motivates them to communicate through art, exchange information, and explore their similarities and differences. In their attempt to meet their goal, students learn to handle their disagreements and ultimately respond to positive behaviours with their own appropriate positive contribution. Consequently, a positive climate of trust is built, promoting relationships of friendship and collaboration, since the aspects of social interaction that lead to the creation of friendly relations are linked to the participation in common activities, effort for clear communication, exchange of information, conflict resolution, and reciprocity (M. Cole \& S. R. Cole, 2002).

Inside the safe framework ensured by drama in education, socio-emotional skills develop naturally, stemming from the need of each child to work and play with the other members of the group (Ball, 2012). Students acquire the sense of emulation, sense of the group, sense of respect for rules, and coordinated collective action. At the same time, they realise the other students' right to also enjoy the activity within a climate of freedom and mutual understanding, as well as to acknowledge the valuable contribution of their peers to the achievement of the end result. Students learn to discipline and harness unbridled selfishness, greed, the feeling of superiority, and to develop responsibility and honesty in their relations with their peers. Students transform from self-centred beings to personalities capable of sharing anything with others (Giannaris, 2001).

In drama in education, just like in real life, the consequences of actions resulting from specific activities and choices may not be ignored. There is the option to repeat events and scenes several times, especially with students making different choices each time, thereby facing different consequences. This repetition allows children to better comprehend the connection between cause and effect, acquire a sense of shared responsibility, flexibility in problem resolution, and to repeat a skill until such time as they own it (Bailey, 1997). Consequently, drama in education allows those participating in its actions to deepen their level of thought, helps them ask questions about how and why, urges them - through innocent tests - to engage in the negotiation of the world that surrounds them, experience the satisfaction of belonging to a group, focus their attention over prolonged periods on developing their skills of listening to and observing the other, and to ultimately communicate with their peers more easily (Dogru, 2015).

Drama in education provides models of constructive interactions and relations. It is a space of social interaction, in which everyone may guide one's feelings, name them, and test them by exercising total control over them (Galazka, 2016). It is an educational approach that 
implements pedagogy of equality for all students and contributes to the development of quality interpersonal relationships.

\section{Method}

\subsection{Aim}

The aim of this study is to demonstrate the contribution of a drama in education programme, implemented among students of a multicultural elementary school during the school year 2014-2015, to the advancement of skills promoting personal empowerment, developing empathy and collaboration, and improving their interpersonal relationships.

\subsection{Research Hypotheses}

The primary hypothesis is that a drama in education activities programme will have a positive influence on the development of social and emotional skills that contribute to the advancement of good interpersonal relations among students of a multicultural classroom.

\subsection{The Participants}

The study was carried out at the $87^{\text {th }}$ intercultural elementary school located in the centre of Athens, where the researcher has been teaching since 2004. Following random selection (draw), the sample included 21 children from the $4^{\text {th }}$ and $5^{\text {th }}$ grade, aged 10-12. They are eleven (11) male and female $4^{\text {th }}$ grade students, four (4) boys and seven (7) girls; and ten (10) male and female $5^{\text {th }}$ grade students, four (4) boys and six (6) girls. Among the participants, nine (9) students come from the Muslim minority of Thrace; seven (7) hail from Albania; one (1) student comes from Syria; one (1) student from Bulgaria; one (1) student from Afghanistan; and two (2) students are of Greek origin. It should be noted that six (6) students are Romani (Roma), of which five (5) are of Albanian descent and one (1) student hails from the Muslim minority of Thrace. Three (3) students are Christian Orthodox, while the remaining eighteen (18) are Muslim. Their mother tongues are Turkish, Greek, Albanian, Bulgarian, Arabic, Romani and Farsi. They are students belonging to the lowest financial strata of Greek society.

\subsection{Research Tools}

The research is a case study, the tools of which include interviews, observation, researcher's $l o g$, as well as the assessments and self-assessments of students who participated in the processes.

The interview was selected as a research tool, since many students have difficulties reading and understanding the Greek language. The good relations between the children and the researcher, as well as the feeling of trust that has been established as a result of their contact with him for many years, were conducive in carrying out the interviews in a climate that was very constructive for the research, allowing to better clarify the students' positions towards the complex issues of the study. The interviews were recorded, individual, of semi-structured form, and carried out in two phases. The first phase took place before the programme's implementation, while the second one immediately after its completion. The questions were 
the same for both phases and based on the questionnaire used by Danochristou (2012).

As the researcher participated in and animated the activities as an integral part of the group he was observing, observation was participatory. To make observation more objective, and in order to enrich the volume of data to be collected, the two female teachers of the classes, the students of which constituted the research sample, also participated in the observation. These observers did not participate in the activities, but completed the Observation Key, as well as additional comments on each of the individual participants, while implementing the programme activities, carried out in the school's multipurpose hall. The same forms were also filled in by the researcher immediately following each meeting. The Observation Key, which was used to record all observations, was designed on the basis of those used by Danochristou (2012) and Katsarou (1998). Field notes were chosen as the observation recording method, as they are recommended for registering human behaviours (Faulkner, Swann, Baker, Bird, \& Carty, 1999). Therefore, data collection from observation was based on the viewpoints of three individuals (i.e., the researcher and the two observers), thereby adding to the objectivity of the recorded observations and comments.

The researcher kept notes in the form of a log. The log contains observations entered in chronological order, related both to the difficulties and the positive aspects of the intervention, researcher concerns and interpretations on research-related issues, data regarding motivation and the activities implemented, dialogue recreations, incident explanations, feelings, reactions, student comments and questions, and observer views.

Every four (4) meetings, the children would evaluate the intervention activities and assess themselves using the drama in education assessment techniques: hot chair and telephone conversations. Evaluation information about the programme was also obtained from the last question of the repeat interviews, as well as from the discussion held with students at the end of each meeting. In the last meeting, a written and visual assessment of the whole programme was made by the students themselves. Therefore, the research tools used in the study were obtained from three viewpoints: "the viewpoint of the researcher, of each student as well as the viewpoint of a neutral third person, which enhances the validity of the endeavour (Altrichter, Posch, \& Somekh, 2001).

\subsection{The Activities Programme}

The programme was completed within seventeen (17) meetings-workshops. The first meeting was held after completion of the initial interviews, on 27 November 2014, while the last one in late April 2015. Each workshop lasted for two (2) teaching hours without a break, once (1) a week. Activity animation was undertaken by the researcher himself, in his capacity as educator, as well as graduate of the National Theatre of Northern Greece drama school.

The aim of the programme was for students to cultivate social and emotional skills and capabilities, which have a positive impact on the development of good interpersonal relations. The programme contains psychomotor activities aimed at the expression of feelings, the development of collaboration and trust, and the cultivation of creativity, imagination, active listening, empathy, and critical thinking. Furthermore, actions that promote self-perception, 
reduce stereotypes and prejudice, and lead to respecting and accepting the cultural identity of the other are also included in the programme.

\section{Findings}

The results both from the participant interviews and the observations and evaluations underline the positive role of drama in education in the development of favourable interpersonal relations.

We, observed that $90.4 \%$ (from $71.4 \%$ originally) of participants in the post-programme interviews offered positive comments for their classmates; $28.5 \%$ (from 9.5\%) stated they trust all students; $76 \%$ (from $47.6 \%$ ) helped their classmates when required; whereas, $95.2 \%$ (from $76.1 \%$ ) stated they play with all students in their class. Finally, 85.7\% (from 80.9\% before programme implementation) stated they play with students of different national descent during recess.

The positive impact of the intervention is also evident from the observation results. It was noted that the average percentage of negative stance and behaviour of each student towards the other students decreases between meetings during the programme implementation. The following table details the average percentage of each student's negative stances and behaviours towards his/her peers in the first four (4) and the last four (4) meetings, as inferred from the comments entered in the Observation Key. Most notably, the positive effect of the activities, given that in all students without any exceptions ( $\mathrm{S}=$ student), negative behaviours in the last four (4) meetings (13-16) are reduced as compared to those recorded in the first four (4) meetings (1-4). 
Table 1. The average percentage of each student's negative stances and behaviours towards his/her peers in the first four (4) and the last four (4) meetings

\begin{tabular}{|l|l|l|}
\hline Students & Meetings 1-4 & Meetings 13-16 \\
\hline S1 & $23 \%$ & $5.5 \%$ \\
\hline S2 & $14.7 \%$ & $6.5 \%$ \\
\hline S3 & $9.6 \%$ & $3 \%$ \\
\hline S4 & $6.9 \%$ & $3.1 \%$ \\
\hline S5 & $2 \%$ & $0 \%$ \\
\hline S6 & $11.5 \%$ & $2 \%$ \\
\hline S7 & $16.4 \%$ & $5.4 \%$ \\
\hline S8 & $9.5 \%$ & $5.4 \%$ \\
\hline S9 & $16.4 \%$ & $3.8 \%$ \\
\hline S10 & $4.8 \%$ & $1.2 \%$ \\
\hline S11 & $7.4 \%$ & $3 \%$ \\
\hline S12 & $11.5 \%$ & $6 \%$ \\
\hline S13 & $13.9 \%$ & $7.4 \%$ \\
\hline S14 & $3.4 \%$ & $1.3 \%$ \\
\hline S15 & $7.1 \%$ & $4 \%$ \\
\hline S16 & $12 \%$ & $5.2 \%$ \\
\hline S17 & $18.5 \%$ & $8.5 \%$ \\
\hline S18 & $16.25 \%$ & $5 \%$ \\
\hline S19 & $18.25 \%$ & $6.25 \%$ \\
\hline S20 & $25 \%$ & $14 \%$ \\
\hline S21 & $21.5 \%$ & $11.7 \%$ \\
\hline & & \\
\hline
\end{tabular}

\section{Discussion}

The group of students who participated in the research processes was indicative of the school's cultural diversity, enriched by children from the immigrant populations residing in Greece and the Muslim minority of Thrace, and children of different religions and mother tongues. It, therefore, constitutes a living entity within which each student interacted more or less with their classmate's cultural specificity. Under these conditions, drama in education was conducive to the students practicing alternative ways of thinking and acting, so that they may assimilate different cultural viewpoints, and showed that students in school may be 
taught humanity in their relationship with themselves and the entire world, as well as improve their relations by promoting humanistic life qualities in the prevailing globalised trends. Students practiced appreciating values and developing skills linked with quality interpersonal relationships: building a good relationship with oneself, collaboration, respect for the other, empathy, expression of solidarity, and respect for diversity. Furthermore, the admissions of students themselves in the final interviews are characteristic of the impact of the activities:

S14: "I understood, with all these things we've been doing with you, that we're all different, we differ. I like our school. If we were all the same, I wouldn't like it. I'd be bored. The more different, the better."

S11: "We did the programme so as not to tease, and to play together. Black and white are all the same, there's no difference. I liked the game with the poppies and the sheep that were all white save one that was black."

S15: "I liked it when we closed our eyes and we were walking and the farewells; I liked everything. I believe I got to know my classmates better."

S16: "I really liked what we did this one time for a kind that the others didn't want because he was another colour. It got me thinking about the children that we don't want because they are from another country, they speak a different language."

In addition, the anonymous self-assessments of the students about the impact the programme had on them, in the last, $\left(17^{\text {th }}\right)$ workshop, move in the same direction. Key reference elements are the better relationship the students had with themselves, collaboration and respect for the other. Students responded as follows:

"I learned how to respect my classmates"; "I learned how to collaborate with others"; "I learned how to behave better towards my friends"; "the whole group learned many things, like good behaviour, respecting the language they speak, their religion and their colour"; "I learned how children who change countries feel"; "I learned to behave well towards my new classmates, boys and girls alike".

Moreover, the artistic evaluation that the students participated in highlights the prevalence of team spirit in their activities, which had a favourable effect on their perceptions and behaviours, regarding the research goals. Students' artistic creations in the seventeenth $\left(17^{\text {th }}\right)$ meeting included theatre scenes surrounded by little hearts, children on stage holding hands attempting to act as a group, and plays entitled, "one for all; we respect one another; we are all different but same".

\subsection{Impact of the Programme on Emotional Intelligence and Empathy}

The development of student empathy and emotional intelligence was of decisive importance for the effectiveness of the intervention. International research and literature have made widely known the contribution of drama in education to the development of empathy, which facilitates the communication among people, improves interpersonal relationships and questions, stereotypes and prejudices (Akyol \& Hamamci, 2007; Bhukhanwala \& Allexsaht-Snider, 2012; Draguns, 2007; McLennan, 2008). 
This intervention was focused on the basic stages of emotional education, such as emotion awareness and expression, allowing the child to verbally express what he/she feels, promoting similarity to others, and investigating different viewpoints concerning a subject (Triliva, Anagnostopoulou, \& Hatzinikolaou, 2008). Interesting to note is that, at the end of each workshop, when the group was discussing what had transpired during the activities, but also during the students' evaluations in the framework of the hot chair and the telephone conversations, the students often referred to the emotions they experienced, actually naming them: "I felt happy", "I was enthusiastic", "I was sad", "I felt angry", "I was ashamed", etc., which is linked to developed emotional capacity.

In addition, students, through role-playing games, forum theatre, improvisations and dramatisations that encouraged: the exchange of views and active listening, practiced identifying their own emotions and those of their classmates; understanding the way of thinking, the intentions and needs of their peers; respecting and accepting different viewpoints on issues that arose within the group; experiencing the world through the psyche of their classmates, thereby recognising the many similarities and common elements they share with those surrounding them. According to Androusou and Magos (2001), dramatic plays operate on the basis of the direct experiential dimension and also distancing oneself from actual events and people. Thus, they allow decompression and cause empathy. This fact may function in other ways than purely positive, as it can surface other conflicts or enhance existing prejudices. Therefore, all educational interventions need to have realised in depth the social framework within which they are being produced. For instance, handling matters in the research that were related to the acceptance of various cultural forms of otherness took place in a group, the members of which had different cultural identities. In other words, the social framework was placed at the epicentre of the cultural, and political framework within which the very subject of the acceptance of otherness is being produced. Consequently, the children's encounter with the different was far from acquiring such characteristics as exotic and folklore, which imply a static viewing of all aspects of difference.

The fourth $\left(4^{\text {th }}\right)$ workshop of the programme aimed exclusively at students exercising emotions and senses. The research results confirmed the findings of previous studies on empathy and drama in education (Akyol \& Hamamci, 2007; Burton \& O'Toole, 2009; Santomenna, 2010). When asked about the programme, the students responded as follows:

S5: "The aim of the programme was for the other children, the ones that come from other countries, to understand how they feel over here. And also for us to understand how we would feel if we behaved badly to them and how we would feel if they behaved badly to us".

S17: "We did the programme to learn about the others (...) and everyone's feelings". Statements and phrases linked to empathy growth were also recorded in those cases (meetings 10,11,12) in which students, on the occasion of an event, were called upon to defend individuals or groups of people who were being discriminated against. Many times, the students, as is ascertained by the reports made by the observers, as well as by the researcher's log, acted empathetically. Either as actors on stage, or as spect-actors of the discussions that followed the event, the students drew their arguments to bring justice where 
necessary from the admission that nobody would like to be in the shoes of the person being discriminated against. They also constantly invoked both their feelings and those of their classmates:

S3: "...we're all the same. We all have hands and we're all people"; "I would say: all right, he's black -but what would you do if you were black?"

S7: "I would tell them not to make fun, because how would they feel if others made fun of them?"

S9: "I would tell them that that's his colour, why won't you play with him? What of your colour was the same?"

S11: "Yes, I would share a desk with him, because they're all the same. Black and white and brown, they're all the same...they're people."

S15: "I would say: why are you making fun of him? What would you do if you were in his shoes?"

Through a Forum Theatre action during the $12^{\text {th }}$ meeting, the empathy impulse urged children to climb on stage and defend the hero, whom the other children would not accept due to his colour. The child who took it upon himself to defend the hero, asked the group: "how would you like it if they didn't want you because you 're black?". At the same meeting, S7 stated that he knows very well how this particular child was feeling. He mentioned that, when he went to Germany, for some time he was feeling stressed in school because he believed they did not want him because he was from elsewhere. Therefore, he assumed that this is how the event protagonist would feel, sharing his own emotional state. According to Stürmer, Snyder, Kropp, and Siem (2006), a developed empathy allows people to recognise aspects of themselves in others and leads them to the belief that there is a similarity between the person asking for help and the one providing it; our research confirmed this view. The conviction that both our self and the other come from the same species put into question one-dimensional beliefs of the pupils, resulting in them expressing their solidarity by going on stage and making themselves active members of their class, in an attempt to correct the injustice.

The students' behaviour highlighted in this case, as well as the role of drama in education in the promotion of an educational model that motivates children to express their interest and solidarity for their peers, and to involve them in potential conversations and discussions related to rules on politeness, and their rights and responsibilities both towards the fellow members of their community and others (Hull, Stornaiuolo, \& Sahni, 2010).

\subsection{Programme Impact on Self-Perception}

The systematic education of students in managing their emotions throughout the intervention resulted in allowing themselves to familiarise them with their emotional world, thereby getting to better know a part of themselves, developing self-perception, and improving their self-image at the same time. 
According to Manion (2007), as reported by Tsiaras (2012), the enhancement of self-perception contributes to the students assuming responsibility for their actions and being able to trust themselves. Consequently, they are capable of identifying and more effectively causing desirable changes pertaining to their personality and their relationships with others.

With this in mind, the intervention comprised actions aimed at the students familiarising themselves with their bodies, as well as with the distinguishing features of other group members. The programme included motor activities with a view to develop psychomotor skills and rhythmic ability, improve motor coordination and motor expression, and auditory perception and creativity, all of which contribute to the cultivation of a more substantial relationship with oneself.

The programme activities urged students to engage in a process of exploration of their selves and their pubic self-portrayal. Students spoke to the team about their external features, things they love, and their habits. More specifically, in the third $\left(3^{\text {rd }}\right)$ meeting, S5 created a human sculpture, inspired from a family photo, using the bodies of his classmates. He subsequently provided the other children detailed information about his family members, his loved ones, and the relationships he has with them. In order for one to emote, cooperate, feel solidarity for his peers, and develop a positive relationship with the others, one must first develop the relationship one has with oneself (Hull et al., 2010). Through this process, realising the complexity of him/herself, the individual may imagine more easily how his/her peers are, better understand them, and establish relations with them (Roth, 2016).

The various psychomotor actions of the programme allowed students to engage in face-to-face interactions, capable of highlighting their individual features, which prevailed over their collective identities. The sixteenth $\left(16^{\text {th }}\right)$ meeting had a positive impact on that prospect, when students, on the occasion of the dramatisation of a story about a poppy that was different, trained them in recognising and accepting the particular characteristics of their personality. S16, during the reflection phase, stated that: "no person is the same as the other", while S10 said that: "for someone to have something special is not a bad thing; they will have to accept it and not be anxious about it".

Focusing on the repeat interview question (Talk to me about yourself), one reaches the conclusion that the students, after the completion of the special programme, are in a position to make more references to observable psychological, as well as interpersonal features of theirs, as can be ascertained from their answers (S1, S3, S4, S5, S6, S8, S10): "I have black hair"; "I'm tall"; "I'm not a Christian girl, I'm a good person with some flaws"; "I get mad easily"; "My eyes are brown"; "I can keep a secret"; "I have brown hair"; "I like being with my friends, I love my parents".

Students' references during their self-descriptions, to not only observable but also psychological and interpersonal features, as indicated by Makri-Botsari (2001), is representative of the middle childhood (ages 7-11), which is also the age of most children in the sample. At this point, it should be noted that six (6) students (S7, S15, S17, S19, S20, S21), at a rate of $28.5 \%$, could not make references to any of their own features before the intervention, not even regarding the ones that others may easily observe (i.e., external characteristics, bodily 
features, possession of materials). By the end of the programme, during the repeat interviews, we discovered that they had a more complete picture of themselves. The students replied as follows:

“I like football, I go to private classes, I like cats (...), I don't like being made fun of (...), I have black hair, black eyes, my hair is black, my eyes are brown (...), I am of regular height, I like singing (...)".

The intervention programme followed an equality pedagogy, respecting student personalities, their cultural traditions and encouraged unhindered expression and equitable transmission of all ideas and views. Students were urged to interact using their mother tongue, talk about celebrations and habits of their sociocultural surroundings, and refer to their own personal experiences. Consequently, their participation in the actions took on a more personal character, thereby contributing to the creation of a cohesive framework that acknowledged each child's particularity without highlighting and promoting it. Students felt safe to expose themselves, since their participation - which respected their personality - transmitted positive messages about themselves, boosting their self-concept. In this case, the current research confirmed Schroeter's (2009) findings, who foresaw the difficulty involved in the creation of a perfectly safe environment-especially when the activities take place in multicultural classrooms - prompts the teacher to secure a sincere climate of mutual respect and equitable participation within the group.

From the recorded remarks of the researcher and the observers one determines that the students who felt uncomfortable and embarrassed in the initial meetings and were hesitant to take initiative and interact with their classmates (S2, S8, S13, S15, S18, S20 and S21), gradually became more self-confident within the group, shed their stress, exchanged views during conversations, and assumed roles in the dramatisations. Some of the students (S18, S21), actually took on leading roles in the actions during the last workshops. Enhancing students' self-esteem and self-perception significantly impacted the boosting of relations among the children who comprised the research sample.

\subsection{Programme Impact on Interpersonal Relations}

The intervention process confirmed our research hypothesis that it would positively affect the interpersonal relationships of participating children.

In addition to the findings detailed hereinabove, it was determined from the researcher $\log$ that students who took the hot seat referred to the effort they made to collaborate, communicate, and cultivate friendships, became closer to the other members of the group. In addition, during the overall assessment of the programme at the seventeenth $\left(17^{\text {th }}\right)$ meeting, the students themselves - anonymously - ascertained the positive impact of the intervention on their acquaintance and relationships with their classmates: "I have learned to respect and trust the others"; "to treat my classmates well"; "I got to know my classmates better and learned things about them"; "I learned to respect my classmates and help them"; "I met new girlfriends"; "I have learned to behave and play better"; "I got to know many children"; "I learned that my classmates are really good guys". 
$\mathrm{S} 5$, when asked at the repeat interviews about the programme, placed great emphasis on improving collaboration, an indication of an improvement of interpersonal relations: "It got me thinking about its purpose and I liked it the most when we got to split into groups. I worked with the other the most, we used to join our friends and when you told us to join children that we knew the least, we got to know how it is to work with them as well. That was really neat".

S12 also referred to the gradual improvement of the collaborative relations that he experienced: "I collaborated with my classmates, I played really well. In the beginning we didn't know one another too well, others were shouting and the like, but then we got to collaborating better".

The prevalence of a climate of collaboration in the programme procedures is highlighted in many students' reports. According to Bayliss and Dodwell (2002), when students become involved in collaborative actions that allow the exploration of artistic expression, such as the activities in our research, they are required to work together selflessly and harmonising themselves with the wants of the other. Team spirit is supported by the entire group, which renders group strength and the strength of each individual member. Repressed feelings, skills, thoughts, and ambitions are liberated, while unusual emotions and expectations are expressed, creating a special situation that gives rise to new personalities and a new team spirit. The current study confirmed these views, as the group was imbued with a team spirit that was being built from meeting to meting and which had a beneficial impact on each participant. It is characteristic that the last meetings were held under particularly collaborative conditions, boosting positive interpersonal relationships among the students. This fact is evident from the notes of both the observers and the researcher. Moreover, the image each student has with regard to their relations with the rest of the group appeared to be gradually improving between meetings; as a matter of fact, this development is more pronounced in those students with the most difficulties communicating (S1, S2, S8, S13, S17, S20). A particular case is that of S21, who appeared to have had the most problematic relations, as compared to the other group members, which is mostly due to reasons related to her personal hygiene. As a result, many students refused to have physical contact with her, distanced themselves from her, while some used derogatory characterisations. The teacher-observer in the classroom confirmed that the same situation also occurred in-class, resulting in the child being particularly lonesome. The efforts made during the programme implementation to improve her relations with the rest of the group had a small positive impact, which is reflected in the child's own responses. In the initial interview, when speaking about the other children in her class, she said: "I feel bad with my classmates, because they make fun of me all the time and they don't want to sit next to me"; "I am not pleased (with the other children's behaviour), because neither they want to be my friends nor do I want to be theirs".

After the programme implementation, her responses change:

"Ifeel well (with the classmates), I'm happy because they are my friends and I play with them"; "yes, I can't complain (about the other children's behaviour), it's only S... who's disgusting".

From the observers' comments and the researcher's log, one can also determine that, in the initial meetings, children with closer connections amongst them operated as microgroups within the class. According to Bikos (2004), the subgroups owe their existence mainly to the 
inability of people to interact equally closely with many other individuals. In our intervention scheme, students in the subgroups were expressing they wished to always work together; they became disturbed or annoyed whenever this wouldn't happen; while on several occasions, they had the tendency to laugh at, or tease, other students. This behaviour resulted in protests, misunderstandings and tension. It was also observed that girls preferred working with girls, whereas similarly boys wished working only with other boys. The embarrassment and anxiety of several students was also evident whenever they participated in groups of students with whom they had no particular personal relations and were supposed to work together for an event to be successful. However, all tensions showed a downward trend the more the students' relations were improving. Students became better acquainted with one another through systematic contact, which occasionally became physical depending on the actions and, gradually, complaints about the random selection of the group they would be assigned to, which was originally a source of reaction, ultimately subsided. Collaboration between both genders was subsequently taking place more easily, and the microgroups started losing their cohesion and the dynamic they had during the first workshops, without however ceasing to exist altogether. In the last meetings, communication and contact between the microgroups was more substantial as compared to the initial workshops. This result also became evident in the more complete and of higher quality execution of the activities of children working in groups, as well as those working in pairs.

It was noted that the positive impact of the intervention on collaboration development started becoming more pronounced from the sixth $\left(6^{\text {th }}\right)$ meeting onwards. This observation confirms the reference by Tsiaras (2004), according to which a minimum number of five (5) sessions is required to raise student's awareness, increase their participation readiness and for this participation to take on a creative character. Bolton (1986) similarly supported that a certain number of workshops are initially required to cultivate trust among children, allowing them to emotionally respond to the activities.

\section{Research Limitations and Delimitations}

This research is subject to the following limitations and delimitations: Poor attendance throughout the year, which is a particularity of intercultural schools, affected the initial number of participants. Therefore, although initially 25 students participated, by the end of the intervention, there were 21 total. In addition, the fact that no permission to video the research was granted, may have resulted in certain information, which would have enriched the research results, to have been lost. Moreover, further study would be useful to ascertain the activity programme impact on students over a longer period of time.

\section{Conclusions}

Drama in education is highlighted through this research as a pedagogical tool that develops a series of qualitative skills, which are necessary in a number of aspects of everyday life. In addition, drama in education is an integrated methodological approach that utilises creative paths of joy and freedom to successfully investigate sensitive sociopolitical issues, such as intercultural coexistence, by cultivating communication behaviours that are residing at the very core of universally accepted humanitarian values. Especially in today's social reality, in 
which the populous presence of immigrants and refugees at schools makes it necessary for school life to embrace tolerance and solidarity, drama in educational processes may widen the perspective of students as regarding the other cultural traditions. Leading them into developing substantial and meaningful interpersonal relationships, necessary for them to become connected to the global community.

\section{References}

Akyol, A. K., \& Hamamci, Z. (2007). The effect of drama education on the level of empathetic skills of university students. Bulgarian Journal of Science and Education Policy, 1, 205-215. htpps://doi.org/10.11114/jets.v6i3.2968

Altrichter, H., Posch, P., \& Somekh, B. (2001). Teachers are Investigating Their Work. Athens: Metechmio.

Androusou, A., \& Magos, K. (2001). The daily educational practice. In A. Androusou, N. Askouni, K. Magos, \& S. Christidou-Lionakis (Eds.), Education: Cultural Differences and Social Inequalities (Vol. B, pp. 13-164). Patras: EAP.

Ball, D. (2012). Dramatherapy with children who have been bullied: Anne Banister Award 2010. Dramatherapy, 34(1), 35-46. https://doi.org/10.1080/02630672.2012.674813

Bayliss, P., \& Dodwell, C. (2002). Building relationships through drama: The action track project. Research in Drama in Education: The Journal of Applied Theatre and Performance, 7(1), 43-60. https://doi.org/10.1080/13569780120113139

Belliveau, G. (2005). An Arts-based approach to teach social justice: Drama as a way to address bullying in schools. International Journal of Arts Education, 3(2), 136-165.

Bhukhanwala, F., \& Allexsaht-Snider, M. (2012). Diverse student teachers making sense of difference through engaging in Boalian theater approaches. Teachers and Teaching: Theory and Practice, 18(6), 675-691. https://doi.org/10.14507/epaa.v23.2051

Bikos, G. K. (2004). Interaction and Social Relations in the Classroom. Athens: Greek Letters.

Bolton, G. (1986). Selected Writings on Drama in Education. London: Longman.

Burton, B., \& O'Toole, J. (2009). Power in their hands: The outcomes of the acting against bullying research project. Applied Theatre Researcher Journal, 10, 1-15.

Cole, M., \& Cole, S. R. (2002). The Development of Children: Cognitive and Psychosocial Development During Infancy and Middle Childhood. Athens: Typothito-Giorgos Dardanos.

Danochristou, M. (2012). Intercultural Music Education and Teaching: The Participatory Coexistence of Foreign Secondary Education Students Through The Traditional Music of Their Countries of Origin (Doctoral thesis, School of Philosophy, Department of Music Studies, University of Athens).

Dogru, S. S. Y. (2015). The effect of creative drama on pre-teaching skills and social 
communication behaviors of children with autism. Studies on Ethno-Medicine, 9(2), 181-189. https://doi.org/10.1080/09735070.2015.11905433

Draguns, J. (2007). Empathy across national, cultural, and social barriers. Report of Empirical Studies, 8(1,2), 5-20. https://doi.org/10.1037/e629922012-003

Faulkner, D., Swann, J., Baker, S., Bird, M., \& Carty, J. (1999). Methodology Manual. Patras: EAP.

Galazka, A. (2016). Presentation: Creating emotional awareness through drama in the second language acquisition. BUKS-Tidsskrift for Børne \& Ungdomskultur.

Giannaris, G. (2001). Theatrical Education and Play. Athens: Grigoris.

Hull, A. G., Stornaiuolo, A., \& Sahni, U. (2010). Cultural citizenship and cosmopolitan practice: Global youth communicate online. English Education, 42(4), 331-367. Retrieved from http://www.jstor.org/stable/23018017

Joronen, K., Konu, A., Rankin, H. S., \& Åstedt-Kurki, P. (2011). An evaluation of a drama program to enhance social relationships and anti-bullying at elementary school: A controlled study. Health Promotion International, 27, 5-14. https://doi.org/10.1093/heapro/dar012

Katsarou, E. (1998). Curriculum Reform using Active Participatory Research: The Example of the Modern Greek Language (Doctoral thesis, School of Philosophy, Department of Pedagogy, University of Athens).

Kuranchie, M. A., \& Addo, H. (2015). Review of the relevance of social competence to child's development: Lessons drawn. Academic Journal of Interdisciplinary Studies, 4(2), 449-454. https://doi.org/10.5901/ajis.2015.v4n2p449

Lindberg, E. K. (2015). Preschool Creative Drama: A Curriculum and its Effects on Learning (Theses, Paper 2).

Mages, W. (2010). Creating a culture of collaboration: The conception design, and evolution of a head start theatre-in-education program. Youth Theatre Journal, 24(1), 45-61. https://doi.org/10.1080/08929091003732989

Makri-Botsari, E. (2001). How do I Perceive Myself? Athens: Greek Letters.

Mavroudis, N., \& Bournelli, P. (2016). The role of drama in education in counteracting bullying in schools. Cogent Education, 3, 1-12. https://doi.org/10.1080/2331186X.2016. 1233843

McLennan, D. M. P. (2008). The benefits of using socio-drama in the elementary classroom: Promoting caring relationships among educators and students. Early Childhood Education Journal, 35(5), 451-456. https://doi.org/10.1007/s10643-007-0195-2

McNaughton, M. J. (2010). Educational drama in education for sustainable development: Ecopedagogy in action, pedagogy. Culture \& Society, 18(3), 289-308. https://doi.org/10.1080/ 14681366.2010 .505460 


\section{Macrothink}

Roth, I. (2016). Multicultural education through cosmopolitanism in Japanese classrooms. Language and Culture, 34, 137-144.

Santomenna, D. (2010). Are there Benefits of Theatre Arts Programs in Schools? (ProQuest Dissertations and Theses, St. John's University). https://doi.org/10.1037/e661142011-001

Schroeter, S. (2009). Theatre in my Toolbox: Using Forum Theatre to Explore Notions of Identity, Belonging and Culture with Francophone Secondary Students in a Context of Diversity (Proquest Dissertations and Theses, York University, Toronto, Canada).

Stürmer, S., Snyder, M., Kropp, A., \& Siem, B. (2006). Empathy-motivated helping: The moderating role of group membership. Personality and Social Psychology Bulletin, 32(7), 943-956. https://doi.org/10.1177/0146167206287363

Triliva, S., Anagnostopoulou, T., \& Hatzinikolaou, S. (2008). Neither Better nor Worse ... Just Different. Athens: Gutenberg.

Tsiaras, A. (2004). The dramatic play in elementary schools. Review of Educational Issues, 9 , $62-76$.

Tsiaras, A. (2012). Dramatic play as a means of developing primary schools students'self-concept. The Journal of Drama and Theatre Education in Asia, 3(1), 47-67.

Bailey, S. (1997). Drama: A powerful tool for social skill development. Disability Solutions, 2(1), 1-15.

\section{Copyright Disclaimer}

Copyright for this article is retained by the author(s), with first publication rights granted to the journal.

This is an open-access article distributed under the terms and conditions of the Creative Commons Attribution license (http://creativecommons.org/licenses/by/3.0/). 